\title{
IMPROVED LUNG FUNCTION TESTS ON CHANGING FROM TOPICAL TIMOLOL: NON-SELECTIVE BETA- BLOCKADE IMPAIRS LUNG FUNCTION TESTS IN ELDERLY PATIENTS
}

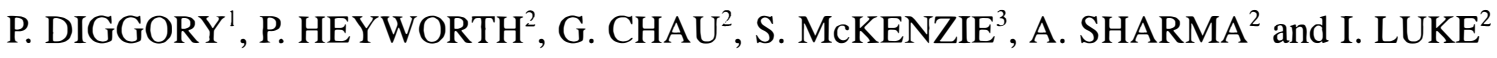 \\ London and Melbourne, Australia
}

\begin{abstract}
SUMMARY
Fifty-two elderly glaucomatous patients, without a history of asthma or obstructive airways disease, who were using topical timolol for control of intraocular pressure were recruited. Their topical therapy was changed to either betaxolol or pilocarpine. The change was associated with improvement in mean peak flow from $278 \mathrm{l} / \mathrm{min}$ to $328 \mathrm{l} / \mathrm{min}(t=5.73, p<0.001)$, mean $\mathrm{FEV}_{1}$ from $1.66 \mathrm{I}$ to $1.85 \mathrm{I}(t=7.09, p<0.001)$ and mean FVC from $2.40 \mathrm{I}$ to 2.64 I $(t=5.07, p<0.001)$. Change to either betaxolol or pilocarpine was associated with improved lung function tests. Lung function tests in a control group of 20 showed no significant changes. Both drugs maintained control of intraocular pressure but betaxolol had fewer ocular side effects.
\end{abstract}

Glaucoma is a common disease in the elderly, affecting approximately $6 \%$ of those over 75 years, ${ }^{1-3}$ and topical therapy with the non-selective beta-adrenergic antagonist timolol is a common medical treatment. ${ }^{4.5}$ Because of the convenient twice-daily dosage and the fact that it has few ocular side effects timolol is a popular drug with patients and ophthalmologists alike.

Drugs administered topically to the eye gain direct access to the circulation by drainage through the nasolacrimal duct and absorption from the nasal mucosa. This avoids first pass metabolism by the liver. Significant amounts of timolol reach the circulation when it is administered topically to the eye $\mathrm{e}^{6,7}$ and this is recognised to cause bronchospasm in patients with asthma ${ }^{8,9}$ or chronic obstructive airways disease. ${ }^{10}$ Topical timolol therapy is considered safe in patients without such a history.

From: Departments of ${ }^{1}$ Geriatric Medicine and ${ }^{2}$ Ophthalmology, St. George's Hospital, London, UK; ${ }^{3}$ National Research Institute for Gerontology, North West Hospital, Melbourne, Australia.

Correspondence to: P. Diggory, Department of Geriatric Medicine, St. James's Hospital, Leeds LS9 7TF, UK.
Elderly people commonly have reversible airflow obstruction, very often undiagnosed..$^{11-14}$ They are at particular risk from respiratory side effects of beta-antagonist therapy. The aim of this study was to ascertain the extent of unrecognised impairment of lung function tests amongst elderly patients already using topical timolol and who had no known contraindication to its use.

\section{MATERIALS AND METHODS}

To provide a group unaffected by beta-antagonists whose intraocular pressure was nevertheless controlled, a group of patients was changed to the cholinergic agent pilocarpine. Substitution of timolol by the more cardioselective betaxolol was used to ascertain whether other patients given a relatively cardioselective beta-antagonist would improve their lung function tests.

Fifty-two patients ( 25 men and 27 women) aged 65-92 years (mean 77.5 years) who were receiving topical timolol for glaucoma were recruited from ophthalmology clinics. A control group of 20 patients (5 men and 15 women) aged 66-91 years (mean 75.8 years) were simultaneously recruited from the same clinics to exclude a learning effect with the spirometer for any changes in lung function tests. Patients and controls had to meet the same enrolment criteria. They were ambulant, not receiving oral beta-blocker or.bronchodilator therapy and not known to have asthma or obstructive airways disease. There was no history of recent respiratory tract infection or heart failure and their intraocular pressures were stable.

The nature of the study was explained to each patient and consent obtained.

Values for peak flow, $\mathrm{FEV}_{1}$ and FVC were obtained using a Micromedical pocket spirometer. ${ }^{15}$ Only those who, after tuition, were adjudged to have consistent technique with the instrument were included in the study, and the values recorded were the best of three attempts at least 
Table I. Change in lung function tests (mean values) between enrolment and review: combined betaxolol and pilocarpine groups

\begin{tabular}{|c|c|c|c|c|c|c|}
\hline & \multicolumn{2}{|c|}{ On enrolment } & \multicolumn{2}{|c|}{$\begin{array}{c}\text { On review } \\
\text { after } 4 \text { weeks }\end{array}$} & \multicolumn{2}{|c|}{$\begin{array}{l}\text { Significance: } \\
\text { pre vs. review }\end{array}$} \\
\hline & Mean & SD & Mean & SD & $t$ & $p$ \\
\hline Peak flow (1/min) & 278 & 99 & 328 & 102 & 5.73 & $<0.001$ \\
\hline $\mathrm{FEV}_{1}(1)$ & 1.66 & 0.57 & 1.85 & 0.57 & 7.09 & $<0.001$ \\
\hline FVC (l) & 2.40 & 0.79 & 2.64 & 0.85 & 5.07 & $<0.001$ \\
\hline $\mathrm{FEV}_{1} / \mathrm{FVC}$ & 0.69 & 0.11 & 0.70 & 0.09 & 1.14 & NS \\
\hline
\end{tabular}

$n=47$; mean age 76.5 years; 22 males, 25 females.

6 hours after a dose of topical timolol. Intraocular pressures were recorded independently at the clinic by ophthalmologists using Goldmann applanation tonometry immediately before performing lung function tests.

Timolol therapy was discontinued and patients randomly allocated to receive either topical $2 \%$ pilocarpine q.d.s. or $0.5 \%$ betaxolol b.d. to both eyes. Exception was made for 1 patient with pilocarpine allergy and 2 patients using both timolol and pilocarpine who were given betaxolol. The controls were likewise assessed but no change was made to their topical medication.

Lung function tests were repeated after a 4-week period on the new therapy, the observer being unaware of the results of the subject's enrolment lung function tests. Intraocular pressures were recorded by clinic staff. Patients were asked whether they had noticed: headache, stinging eyes, change in vision, or any other side effect. If they had noticed a side effect they were asked whether they would find long-term therapy with the drug intolerable. Previous therapy was reinstated and the patient returned to his or her ophthalmologist for review of therapy in the light of the lung function test results obtained during the study.

For statistical analysis independent $t$-tests were used to test significance of differences between the group changes in mean peak flow, $\mathrm{FEV}_{1}, \mathrm{FVC}$ and $\mathrm{FEV}_{1} / \mathrm{FVC}$ between enrolment and review. Paired sample $t$-tests were used to
Table II. Change in lung function tests (mean values) between enrolment and review: control group

\begin{tabular}{|c|c|c|c|c|c|c|}
\hline & \multicolumn{2}{|c|}{ On enrolment } & \multicolumn{2}{|c|}{$\begin{array}{c}\text { On review } \\
\text { after } 4 \text { weeks }\end{array}$} & \multicolumn{2}{|c|}{$\begin{array}{l}\text { Significance: } \\
\text { pre vs. review }\end{array}$} \\
\hline & Mean & SD & Mean & SD & $t$ & $p$ \\
\hline Peak flow $(1 / \mathrm{min})$ & 255 & 76 & 253 & 86 & 0.19 & NS \\
\hline $\mathrm{FEV}_{1}(\mathrm{l})$ & 1.47 & 0.47 & 1.49 & 0.43 & 0.55 & NS \\
\hline FVC (l) & 2.10 & 0.59 & 2.14 & 0.54 & 0.14 & NS \\
\hline $\mathrm{FEV}_{1} / \mathrm{FVC}$ & 0.70 & 0.09 & 0.70 & 0.11 & 0.20 & NS \\
\hline
\end{tabular}

$n=16$; mean age 75.5 years; 2 male, 14 female.

test significance of changes in mean intraocular pressures in the betaxolol and pilocarpine groups.

\section{RESULTS}

Fifty-two patients were enrolled in the study. Twentyseven were changed to betaxolol and 25 to pilocarpine. Forty-seven completed the trial. Four using pilocarpine and 1 using betaxolol withdrew because of ocular side effects. Three of 20 controls failed to attend follow-up and 1 developed left ventricular failure.

Amongst patients completing the study there was significant improvement in mean peak flow, mean $\mathrm{FEV}_{1}$ and mean FVC between enrolment and review at 4 weeks. The control group showed no significant changes in recorded lung function tests between enrolment and review (Tables I, II). More importantly, 19 (40\%) of the 47 patients had a clinically significant improvement in their lung function tests, defined as a $15 \%$ or greater increase in peak flow, FEV $_{1}$ and FVC. ${ }^{16}$

Change of topical therapy from timolol to either betaxolol or pilocarpine was associated with improvement in lung function tests. There was no significant difference in the changes in mean values between the betaxolol and pilocarpine groups. Both showed significant improvement compared with controls (Table III).

Betaxolol therapy was associated with fewer ocular side effects than pilocarpine. Almost all of the 21 using pilo-

Table III. Observed change in mean values of lung function between enrolment and review for betaxolol, pilocarpine and control groups, and significance of changes in treatment groups between enrolment and review compared with those of the control group

\begin{tabular}{|c|c|c|c|c|c|c|c|}
\hline & \multicolumn{3}{|c|}{$\begin{array}{l}\text { Observed changes in mean values of lung } \\
\text { function test between enrolment and review }\end{array}$} & \multicolumn{4}{|c|}{$\begin{array}{l}\text { Significance of the differences in } \\
\text { changes between groups }\end{array}$} \\
\hline & \multirow[b]{2}{*}{$\begin{array}{l}\text { Betaxolol group } \\
\quad(n=26)\end{array}$} & \multirow[b]{2}{*}{$\begin{array}{l}\text { Pilocarpine group } \\
\quad(n=21)\end{array}$} & \multirow[b]{2}{*}{$\begin{array}{l}\text { Control group } \\
\quad(n=16)\end{array}$} & \multicolumn{2}{|c|}{ Betaxolol vs. control } & \multicolumn{2}{|c|}{ Pilocarpine vs. control } \\
\hline & & & & $t$ & $p$ & $t$ & $p$ \\
\hline Peak flow (1/min) & +47 & +53 & -2 & 3.36 & 0.002 & 3.27 & 0.003 \\
\hline $\mathrm{FEV}_{1}(\mathrm{l})$ & +0.19 & +0.18 & +0.02 & 3.08 & 0.004 & 2.88 & 0.007 \\
\hline FVC (1) & +0.25 & +0.20 & +0.04 & 4.07 & 0.001 & 2.33 & 0.028 \\
\hline
\end{tabular}

+ , indicates an increase in mean values; - , indicates a decrease in mean values.

There was no significant difference in mean values of lung function tests between the two drug groups.

Table IV. Side effects experienced (percentages in brackets)

\begin{tabular}{lcccc}
\hline & Stinging eyes & Headaches & Altered vision & Drug would be intolerable \\
\hline Betaxolol group $(n=26)$ & $16(62 \%)$ & $1(4 \%)$ & 0 & $(4 \%)$ \\
Pilocarpine group $(n=21)$ & $17(81 \%)$ & $14(66 \%)$ & $5(24 \%)$ & $4(19 \%)$ \\
\hline
\end{tabular}


Table V. Changes in mean intraocular pressures

\begin{tabular}{lcc}
\hline & $\begin{array}{c}\text { Pilocarpine group Betaxolol group } \\
(n=21)\end{array}$ & $(n=26)$ \\
\hline Pressure on enrolment $(\mathrm{mmHg})$ & 21.1 & 18.8 \\
Mean pressure on review $(\mathrm{mmHg})$ & 18.5 & 18.1 \\
Change in pressure $(\mathrm{mmHg})$ & $-2.6^{*}$ & $-0.7 \mathrm{NS}$ \\
\hline
\end{tabular}

- , indicates a decrease. ${ }^{*} p<0.001 ; \mathrm{NS}$, not significant.

carpine complained of stinging eyes, most claimed headache, 5 reported altered vision and 4 said that they would find the drug intolerable as long-term therapy. In addition, 4 patients using pilocarpine withdrew from the trial because of ocular side effects, but only 1 of those changed to betaxolol withdrew (Table IV).

No patient required additional topical therapy as a result of stopping timolol. In the pilocarpine group there was a small, but statistically significant, fall in mean intraocular pressure (Table V).

\section{DISCUSSION}

The majority of patients with glaucoma are elderly. They have a high prevalence of unrecognised bronchospasm. Elderly people are less likely to complain of symptoms of shortage of breath. This may be because other medical conditions predominate, together with a stoical attitude to disease.

This study demonstrates that many elderly patients, without history of bronchospasm and apparently using topical timolol without complaint, are experiencing significant impairment of lung function tests. Beta-antagonists are contraindicated in patients who demonstrate reversible airflow obstruction and in our study $40 \%$ of patients showed such clinically significant reversibility. The improvement in lung function tests was seen in both the betaxolol and pilocarpine groups and there was no increase in mean intraocular pressure in either group.

We believe the extent of unrecognised impairment of lung function tests induced by topical timolol is too high to justify using it in the elderly unless lung function tests are performed before and after starting treatment. Pilocarpine therapy is effective in controlling intraocular pressure but it has a high incidence of local side effects, and potential systemic adverse reactions include confusion. ${ }^{17}$ This, and its four times daily administration, is likely to result in poor compliance in the elderly. If medical therapy with topical beta-antagonists is deemed essential we recommend a cardioselective agent be chosen.

We should like to thank Mr. G. Thompson for his help and advice. The project was aided by an equipment grant from the British Geriatric Society.
Key words: Bronchospasm, Elderly patients, Lung function tests, Respiratory impairment, Topical beta-antagonists.

\section{REFERENCES}

1. Gibson JM, Rosenthal AR, Lavery J. A study of the prevalence of eye disease in the elderly in an English community. Trans Ophthalmol Soc UK 1985;104:196-203.

2. Kini MM, Leibowski HM, Colton T, Nickerson RJ, Ganley J, Dawber TR. Prevalence of senile cataract, diabetic retinopathy, senile macular degeneration and open angle glaucoma in the Framingham study. Am J Ophthalmol 1978;85:28-33.

3. Vernon SA, Henry DJ, Cater L, Jones SJ. Screening for glaucoma in the community by non-ophthalmologically trained staff. Eye 1990;4:89-97.

4. Zimmermen TJ, Kaufman HE. Timolol: a beta adrenergic blocking agent for the treatment of glaucoma. Arch Ophthalmol 1977;95:601-4.

5. Radius RL, Diamond GR, Pollack IP, Langham E. Timolol: a new drug for the management of chronic simple glaucoma. Arch Ophthalmol 1978;96:1003-8.

6. Alvan G, Caissendorff B, Seideman P, Widmark K, Widmark G. Absorption of ocular timolol. Clin Pharmokinet 1980;5:95-100.

7. Affrime MB, Lowenthal DT, Torbert JA, Shirk J, Eidelson B, Cook T, Onesti G. Dynamics and kinetics of ophthalmic timolol. Clin Pharmacol Ther 1980;27:471-7.

8. Jones FL, Ekberg NG. Exacerbation of asthma by timolol. N Engl J Med 1979;301:270.

9. Charan NB, Lakshminarayan S. Pulmonary effects of topical timolol. Arch Intern Med 1980;140:843-4.

10. Schoene RB, Martin TR, Charan NB, French CL. Timolol induced bronchospasm in asthmatic bronchitis. JAMA 1981;245:1460-1.

11. Burr ML, Charles TJ, Roy K, Seaton A. Asthma in an elderly population: an epidemiological survey. BMJ 1979;1: 1041-4.

12. Caird FI, Akhtar AJ. Chronic respiratory disease in the elderly: a population survey. Thorax 1972;27:764-8.

13. Banerjee DK, Lee GS, Malik SK, Daly S. Underdiagnosis of asthma in the elderly. Br J Dis Chest 1987;81:23-9.

14. Horsley JR, Sterling IJN, Waters WE, Howell JLB. Respiratory symptoms among elderly people in the New Forest area as assessed by postal questionnaire. Age Ageing 1991;20:325.

15. Chowienczyk J, Lawson CP. A pocket sized device for measuring forced expiratory volume in one second and forced vital capacity. BMJ 1982;285:15-17.

16. Snider GL, Woolf CR, Kory RC, Ross J. Criteria for the assessment of reversibility in airways obstruction. Report of the committee on emphysema, the American College of Physicians. Chest 1974;65:552-63.

17. Reyes PF, Dwyer BA, Schwartzman RJ, Sacchetti T. Mental status changes induced by eye drops in dementia of Alzheimer's type. J Neurosurg Psychiatry 1989;50:113-5. 